\title{
Pengembangan Tradisi Geridhoan dan Endhog-Endhogan dalam Meningkatkan Daya Tarik Wisata Syariah melalui Festival GERIDHOGAN di Banyuwangi
}

\author{
Moch. Robis, Bima Rafly Fachrezzi, Abdillah Akhsan \\ Akutansi, Fakultas Ekonomi dan Bisnis, Universitas Airlangga \\ moch.robis-2016@feb.unair.ac.id
}

DOI: https://doi.org/10.21107/dinar.v6i2.6468

\begin{abstract}
Abstrak
Tradisi dan Budaya adalab kebiasaan yang dilakukan oleh orang-orang yang telah menjadi nilai-nilai dan warisan turun-temurun. Salah satu tradisi dan budaya adalah Geridhoan dan Endhog-Endhogan. Tradisi ini adalah tradisi dalam menyambut ulang tahun Nabi Mubammad Shallalabu 'Alaibi Wassallam. Geridhoan adalah tradisi bagi kaum muda untuk menemukan jodoh mereka dengan memberi isyarat dengan bambu sehingga ini jauh dari perzinahan dan Endhog-Endhogan adalah parade telur hias yang memiliki filosofi tersendiri.

Fokus penelitian ini adalah bagaimana mengungkapkan fenomena tradisi masyarakat yang dijadikan sebagai produk festival Islami. Jenis penelitian menggunakan metode penelitian kualitatif karena penelitian ini mencoba mengungkap fenomena yang berkenaan kegiatan fetival sosial budaya masyarakat. Secara umum penelitian ini adalah penelitian lapangan (field Research), yaitu penulisan langsung ke objek penelitian untuk mengetahui secara langsung perilaku sosial yang terjadi di masyarakat. taknik studi dokumentasi diperlukan untuk bahan informasi penunjang, dan sebagai bagian berasal dari kajian sumber data pokok yang berasal dari observasi partisipisan dan wawancara mendalam.

Hasil dari penelitian ini mengungkapkan babwa kedua festival tersebut dapat meningkatkan kunjungan wisatawan dan dapat meningkatkan pendapatan daerah, meningkatkan kesejabteraan lokal, dan mengembangkan pariwisata syariah di Kabupaten Banyuwangi.
\end{abstract}

Kata Kunci: Geridhoan, Endhog-Endhogan, Festival 


\section{Dinar. Vol 6, No 2: Agustus 2019. 123-134 \\ ISSN: 2460-9889 (Cetak) \\ ISSN: 2580-3565 (Online)}

\section{PENDAHULUAN}

Kebudayaan merupakan segala perbuatan manusia,misalnya cara ia menghayati kematian dan membuat upacara-upacara untuk menyambut persitiwa itu, demikian juga mengenai kelahiran, sopan santun waktu makan, pertanian, perburuan, cara-cara menghiasi badan dan rumahnya (Pearsen, 1998:11). Selanjutnya, Tradisi menurut Bastomi (1984:11) adalah roh dari sebuah kebudayaan. Dengan adanya tradisi, maka sistem kebudayaan akan menjadi kokoh. Tradisi akan sesuai dengan situasi dan kondisi dari pewarisnya. Sebagai funginya sendiri, Kebudayaan dan Tradisi merupakan alat yang digunakan untuk mempromosikan nilai-nilai budaya dan identitas negara (Cheang,2009). Hal ini sejalan dengan perkataan Harmawati dkk (2016) yang mengatakan bahwa Kebudayaan dengan alat Festival dapat digunakan sebagai melestarikan nilai tradisi karena akan mampu banyak menarik kalangan untuk melestarikannya.

Indonesia merupakan negara kepulauan yang memiliki berbagai budaya. Budaya tiap tiap daerah ini memiliki sisi keunikan dan dapat dimanfaatkan untuk meningkatkan sebagai sebuah daya tarik wisata. Mahardika (2015) mengatakan bahwa budaya yang unik memiliki potensi besar sebagai daya tarik wisata karena wisatawan akan senantiasa tertarik untuk menyaksikan apa yang tidak mereka miliki. Semakin sebuah daerah memiliki tradisi atau budaya yang unik, makin kuat daya tarik daerah tesebut sebagai destinasi wisata.

Indonesia selain menjadi negara yang kaya akan budaya dan tradisi juga menjadi negara yang memiliki penduduk mayoritas beragama muslim. Hal inilah yang membuat beberapa budaya di Indonesia juga memiliki nilai-nilai keislaman. Potensi dari budaya Indonesia yang memiliki nilai-nilai keislaman inilah yang harus dimanfaatkan sehingga dapat meningkatkan daya tarik wisata syariah. Wisata syariah memiliki pengertian proses penggabungan nilai-nilai keislaman dalam kegiatan wisata (Ramadhany dan Ridlwan,2018). Hal ini juga ditegaskan makna keislaman dalam sebuah budaya dan tradisi pada hukum islam Qawa'id Fiqhiyyah dalam al 'adatu mubakkamah bahwa adat kebiasaan dapat dijadikan hukum, dimana hal ini merupakan hal yang bermanfaat dan tidak bertentangan dengan syara'

Salah satu budaya dan tradisi yang memiliki nilai-nilai keislaman adalah ada di kota Banyuwangi, tepatnya di desa Macanputih, Kecamatan Kabat. Tradisi ini masyarakat sering menyebutnya dengan tradisi Geridhoan. Tradisi ini adalah tradisi yang dilakukan sehari sebelum hari maulid nabi Muhammad Shallalalhu 'alaihi wassalam. Tradisi ini dilanjutkan dengan tradisi Endhog-Endhogan pada hari maulid nabi Muhammad Shallallahu 'alaihi wassalam. Tradisi Geridhoan merupakan tradisi bagi pemuda-pemudi masyarakat using (suku di Banyuwangi) untuk mencari calon pasangan hidupnya. Tradisi ini diawali dengan berbagai atraksi yang dilakukan oleh masyarakat sekitar. Sela-sela pada acara tersebut, pemuda banyuwangi yang akan mencari pasangannya, maka akan mengendap-endap untuk mengintip dan menyapa si gadis dari balik dinding dapur yang masih terbuat dari gedheg bambu. Pemuda akan memasukkan lidi melalui selasela gedheg. Si gadis akan meresponnya dengan cara mematahkan ujung lidi. Respon ini 


\section{Dinar. Vol 6, No 2: Agustus 2019. 123-134 \\ ISSN: 2460-9889 (Cetak) \\ ISSN: 2580-3565 (Online)}

menandakan bahwa si gadis menerima kehadiran dari pemuda tersebut. Lalu pemuda boleh bertamu akan tetapi dengan kedua orangtuanya. Dimana biasanya tidak lama kemudian keduanya segera melangsungkan pernikahan, sehingga tradisi Geridhoan ini dapat meminimalisir perzinahan. Tradisi Endhog-Endhogan adalah tradisi yang dilakukan dengan pawai telur hias dengan diiringi sholawat kepada Nabi Muhammad Shallallahu 'alaihi wassalam.

Tradisi Geridhoan dan Endhog-Endhogan merupakan tradisi di kota Banyuwangi yang unik dan dapat dimanfaatkan menjadi sebuah potensi daya tarik wisata. Santoso dan Argubi (2018) mengatakan dalam penelitiannya bahwa daerah yang memiliki sisi daya tarik wisata syariah adalah ada pada keunikannya dan kesliannya. Selain itu, nilai-nilai keislaman yang dijaga dalam suatu daerah. Aesthetika (2012) mengatakan bahwa dalam menarik wisatawan agar daya tarik wisata berkembang adalah dengan cara Event Festival, sehingga dapat meningkatkan pendapatan daerah. Hal tersebut sejalan dengan pernyataan Richards (2007) yang menyatakan bahwa budaya selain memiliki fungsi mendukung identifikasi sosial, juga dapat sebagai sumber pemasukan dan kegiatan ekonomi. Hal inilah yang melatarbelakangi penulis untuk mengangkat tradisi Geridhoan dan Endhog-Endhogan kedalam sebuah program Event Festival kota Banyuwangi. Banyuwangi sebagai kota dengan berbagai festival akan tetapi belum memiliki festival berbasis nilai-nilai islami, padahal dengan mengangkat tradisi Geridhoan dan EndhogEndhogan dapat meningkatkan daya tarik wisata syariah di kota Banyuwangi.

\section{TINJAUAN PUSTAKA}

\section{Tradisi, Budaya, dan Perspektif islam memandang Keduanya}

Marzuki (2006) menyatakan bahwa Tradisi adalah warisan atau norma adat istiadat, kaidah-kaidah, harta-harta. Tradisi diperpadukan dengan aneka ragam perbuatan manusia dan diangkat dalam keseluruhannya. Manusia yang membuatnya, yang menerima, dan manusia pula yang mengubahnya bahkan menolaknya. Inilah yang akan membentuk Kebudayaan dimana kebudayaan merupakan cerita perubahan-perubahan manusia yang selalu member wujud baru pada pola kebudayaan yang sudah ada.

Fungsi Tradisi dan Kebudayaan bermacam-macam. Pertama, Tradisi dan Kebudayaan dapat mendukung identifikasi sosial dari sebuah daerah sehingga daerah tersebut memiliki identitas sosial tersendiri sehingga berbeda dari yang lain (Alma'arif, 2015). Kedua, Tradisi dan Kebudayaan dapat dijadikan untuk mempromosikan nilai-nilai budaya (Widiastuti, 2013). Alat promosi inilah yang akan membuat tradisi dan kebudayaan tersebut semakin terjaga dan terus ada karena akan mampu menarik kalangan untuk melestarikannya. Ketiga, Tradsi dan Kebudayaan dapat digunakan sebagai Kegiatan ekonomi. Hal ini terjadi karena Tradisi dan Kebudayaan akan menjadi daya tarik wisata pada suatu daerah, terlebih lagi daerah yang semakin memiliki Tradisi dan Kebudayaan yang unik akan berpotensi besar mendatangkan wisatawan karena ingin melihat apa yang tidak mereka miliki di daerahnya (Wekke, 2013). 


\section{Dinar. Vol 6, No 2: Agustus 2019. 123-134 \\ ISSN: 2460-9889 (Cetak) \\ ISSN: 2580-3565 (Online)}

Agama Islam dalam memandang kebudayaan adalah suatu kearifan lokal dan produkproduk kebudayaan yang produktif dan tidak mengotori aqidab untuk tetap eksis. Agama Islam akan menjadi sebuah naratif yang akan menyelinap masuk ke dalam 'dunia lokal' tersebut jika terjadi perbedaan mendasar. Agama dengan tegas mengatur hubungan manusia dengan tuhan dan manusia dengan manusia (Hidayat Fatmah Tauvik \& Arif, 2016). Sedangkan budaya memberikan ruang gerak yang longgar (Santosa \& Argubi, 2018). Dimana keduanya memiliki tujuan yang sama, yakni memanusiakan manusia dan membangun masyarakat yang beradab dan berperikemanusiaan.

Dalam syariat Islam, terdapat landasan hukum yang beranama 'urf. 'urf adalah sesuatu yang tidak asing lagi bagi masyarakat karena telah menjadi kebiasaan dan menyatu dengan kehidupan mereka baik melalui perkataan maupun perbuatan (Setiyawan, 2012). Para ulama berpendapat bahwa 'urf dan adat adalah sama. Hal ini berdasarkan defiini ulama fiqh: urf adalah sesuatu yang dianggap umum oleh manusia dan terus diberlakukan, baik itu berupa ucapan ataupun gerakan dan itu sama dengan adat" (Zulaekah \& Kusumawati, 2016).

Kaidah diatas menurut ulama adalah adat kebiasaan dan urf dapat dijadikan sebuah sandaran untuk menetapkan hukum syar'i apabila tidak terdapat nash syar'i atau lafadh shorih (tegas) yang bertentangan dengannya. Hal ini dikuatkan oleh hadist:

"Ketika Nabi Muhammad Shallallahu 'alaihi Wassallam datang di Madinah, mereka (penduduk kota) telah (terbiasa) memberi uang muka pada buah-buahan untuk satu tahun. Maka Nabi bersabda: "Siapa saja yang member uang muka pada buah-buahan, maka serahkanlah uang muka tersebut pada ukuran (takaran) tertentu dan timbangan tertentu serta waktu yang tertentu'. Rasulullah shallallahu 'alaihi wasallam juga bersabda: .

"Dari Miswar bin Makbramah dan Marwan, Nabi shallallahu 'alaibi wasallam bersabda:

"Demi Tuban yang jiwaku berada pada kekuasaan-Nya, mereka (kaum Musyrik) tidaklah meminta suatu kebiasaan (adat), dimana mereka mengagungkan bak-bak. Allah, kecuali aku kabulkan permintaan mereka." (HR.al-Bukhari[2581]).

Dalam riwayat lain disebutkan:

"Ingatlah, demi Allah, mereka (orang-orang musyrik) tidak mengajakku pada hari ini terbadap suatu kebiasaan, dimana mereka mengagungkan hak-hak. Allah, dan tidak mengajukku suatu bubungan, kecuali aku kabulkan ajakan mereka." (HR. Ibnu Abi Syaibah, [36855]).

Hadits di atas memberikan penegasan, bahwa Islam akan selalu menerima ajakan kaum Musrik pada suatu tradisi yang membawa pada pengagungan hak-hak Allah dan ikatan silaturrahmi. Hal ini membuktikan bahwa Islam tidak anti tradisi. Bahkan mengapresiasi tradisi yang dapat membawa pada kebaikan.

Setiyawan (2012) menjelaskan syarat-syarat 'urf dapat dijadikan sebagai sandaran hukum, yakni 'urf harus berlaku secara jumuk, artinya 'urf harus dimengerti dan diterima oleh lapisan 


\section{Dinar. Vol 6, No 2: Agustus 2019. 123-134 \\ ISSN: 2460-9889 (Cetak) \\ ISSN: 2580-3565 (Online)}

masyarakat pada daerah tertentu. 'urf juga tidak bertentangan dengan Nash Syar'i. Hal ini sesuai dengan firman allah yang menyatakan bahwa adat kebiasaan yang bertentangan dengan agama tidak dapat dijadikan sebagai sandaran sebagaimana pada surah az-zukhruf ayat 23-24. "urf hanya berlaku sudah sejak lama dan bukan 'urf baru dan'urf juga tidak berbenturan dengan Tashrih (Ketegasan seseorang dalam sebuah masalah).

\section{Daya Tarik Wisata}

Undang undang no. 10 tentang kepariwisataan menyatakan bahwa daya tarik wisata adalah segala sesuatu yang memiliki keunikan, keindahan, dan nilai yang berupa keanekaragaman kekayaan alam, budaya, dan hasil buatan manusia yang menjadi sasaran atau tujuan kunjungan wisatawan. Suatu tempat yang telah menjadi daya tarik wisata tentunya harus punya kriterianya. Jaelani, (2017) mengemukakan bahwa tempat wisata tergantung pada 3A (Attraction) Atraksi, (Accesibility) Akses yang mudah, dan (Amenities) Fasilitas.

Atraksi adalah segala sesuatu yang terdapat di daerah tujuan wisata yang merupakan daya tarik agar orang-orang mau datang dan berkunjung ke suatu tempat tujuan wisata diantaranya adalah: Benda benda yang tersedia dan terdapat di alam semesta, contohny adalah iklim, bentuh tanah dan pemandangan, Hutan belukar, Flora danfaunah, dan pusat kesehatan; Hasil ciptaan manusia, yakni sejarah, budaya, dan agama; Monyme bersejarah dan sisa peradaban masa lampau; Kesenian rakyat dan kerajinan tangan; Acara tradisional, pameran dan festival serta rumah ibadah.

Unsur yang terpenting dalam aksesibilitas (Accesibility) adalah transportasi, yakni frekuensi penggunaannya, kecepatan yang dimiliki dapat mengakibanyak jara seolah menjadi dekat. Selain itu, prasarana meliputi jalan, jembatan, terminal, stasiun, dan bandara. Kondisi prasarana yang baik akan membuat lanju transportasi optimal.

Fasilitas (amenities) pariwisata ini tidak terlepas dari akomodasi perhotelan. Adapun sarana-sarana penting yang berkaitan antara lain, akomodasi hotel, restoran, air bersih, komunikasi, dan hiburan.

\section{Festival dan Event}

(Fallasi, 1997) mengatakan bahwa Festival adalah suatu peristiwa atau kejadian penting, suatu fenomena sosial yang hakekatnya dijumpai dalam semua kebudayaan manusia. Adapun jenis jenis festival sendiri yakni, festival film, festival musik, festival seni dan festival budaya, Sementara Getz (1997) menyampaikan bahwa event adalah suatu camuran unik dari durasi, engaturan, pengurus, dan orang-orangnya. Event dibedakan menjadi public event dan private event. Public event adalah perayaan budaya, seni atau hiburan, bisnis atau perdagangan, kompetisi olahraga, pendidikan dan ilmu pengetahuan. Sedangkan Private event meliputi perayaan pribadi seperti liburan keluarga atau pesta ulangtahun.

\section{Tradisi Geridhoan dan Endhog-Endhogan}


Geridhoan dalam bahasa using memiliki arti saling menggoda (Nggridu= menggoda), hal ini berarti bahwa Geridhoan adalah budaya lokal dalam proses melakukan godaan terhadap lawan jenis. Pranoto (2014) menyatakan bahwa Geridhoan ini dilaksanakan setiap tahun bersamaan dengan peringatan Maulid Nabi Muhammad Shallallahu 'alaihi Wasallam yang selalu diadakan secara besar-besaran dan merupakan serangkaian perayaan Maulid besar di kabupaten Banyuwangi, di desa Macan putih, Kecamatan Kabat. Hal yang menarik adalah masyarakat Using Banyuwangi percaya bahwa di bulan maulid nabi adalah bulan yang baik untuk mencari jodoh dan melakukan pernikahan bagi pasangan muda mudi.

Awalnya, Geridhoan di awali dengan pemuda yang mengincar seorang gadis harus tau terlebih dahulu dimana si gadis tersebut tinggal. Kemudian, pada malam hari ketika si gadis sibuk membantu keluarganya memasak didapur, sang pemuda datang mengendap - endap untuk mengintip dan menyapa si gadis dari balik dinding dapur yang umumnya msaih terbuat dari gedheg bambu. Sambil berupaya menyapa si gadis, si pemuda juga memberi isyarat kepada si gadis tentang perasaan dan maksud kedatangannya, dengan cara memasukkan batang lidi melalui sela - sela gedheg. Dan si gadis yang sudah paham dengan isyarat tersebut kemudian meresponnya dengan cara mematahkan ujung lidi. Respons tersebut sekaligus sebagai tanda bahwa si gadis sudah mulai terbuka hatinya untuk menerima kehadiran sang pemuda. Keesokan harinya baru dilaksanakan tradisi endhog - endhogan

Endhog- endhogan adalah tradisi masyarakat Banyuwangi dalam memperingati kelahiran Nabi Muhammad SAW. Tradisi endhog - endhogan menggunakan endhog atau telur. Endhog yang digunakan dalam tradisi endhog - endhogan ditusuk dengan sebilah bambu kecil yang mirip dengan tusuk sate, namun ukurannya lebih panjang dan dihias dengan hiasan bunga dari kertas yang disebut "kembang endhog". Kumpulan dari kembang endhog di tancapkan pada batang pohon pisang yang sudah dihias yang disebut jodhang. Satu jodhang biasanya berisi kembang endhog sebanyak 33 atau 99 buah, angka yang menjadi symbol dalam Islam. Kemudian kumpulan jodhang itu akan di arak keliling kampung dengan iringan musik hadrah (rebana).

\section{METODE PENELITIAN}

Jenis penelitian yang digunakan adalah metode penelitian kualitatif. Bogdan dan Taylor mendefisinikan metodologi kualitatif sebagai prosedur penelitian yang menghasilkan data deskriptif berupa kata-kata tertulis atau lisan dari orang-orang dan perilaku yang dapat diamati. Menurut keduanya, pendekatan dengan metode kualitatif diarahkan pada latar dan individu tersebut secara utuh (bolistic) Diantara alasan pengambilan metode penelitian kualitatif ini adalah karena penelitian ini mencoba mengungkap fenomena yang berkenaan kegiatan fetival sosial budaya masyarakat. Selain iitu, metode ini sesuai bila peneliti hendak mendapatkan wawasan tentang yang baru sedikit diketahui, karena sampai saat ini masih kurang penelitian terhapan 
festival ini. Alasan berikutnya, karena metode kualitatif dapat memberikan rincian yang konpleks tentang fenomena yang sulit diungkapkan oleh metode kuantitatif.

Secara umum penelitian ini termasuk juga dalam jenis penelitian lapangan (field Research), yaitu penulisan langsung ke lapangan atau keobjek penelitian untuk mengetahui secara langsung perilaku sosial yang terjadi di masyarakat. Teknik studi dokumentasi diperlukan untuk bahan informasi penunjang, dan sebagai bagian berasal dari kajian sumber data pokok yang berasal dari observasi partisipisan dan wawancara mendalam.

Menurut Cartwright dalam bukunya (Wardiyanta, 2010), observasi adalah suatu proses melihat, mengamati dan mencermati serta merekam perilaku secara sistematis untuk suatu tujuan tertentu. Observasi adalah suatu kegiatan mencari data yang digunakan untuk memberikan suatu kesimpulan atau diagnose.

Objek dari pengamatan ini adalah perilaku masyarakat di daerah macan putih mulai dari faktor, latar belakang dan pengaruh pkeagamaan dalam kehidupan sosiologi keagamaan pengikut. Pengamatan dilakukan dengan cara observasi partisipasi yaitu observasi berinteraksi dengan observiewer (para jama'ah pengajian).

Menurut Maleong dalam buku Hardiansyah menyatakan bahwa wawancara adalah percakapan dengan maksud tertentu yang dilakukan oleh dua pihak yaitu pewancara (yang mengajukan pertanyaan) dan narasumber (yang memberikan jawaban atas pertanyaan tersebut). Wawancara terencana, yaitu peneliti melakukan wawancara dengan subjek penelitian sesuai bahan pertanyaan yang telah disiapkan oleh peneliti.

Menurut (Wardiyanta, 2010), studi dokumentasi adalah salah satu metode pengumpulan data kualitatif dengan melihat atau menganalisis dokumen-dokumen yang dibuat oleh subjek sendiri atau oleh orang lain berupa foto. Studi dokumentasi dalam penelitian ini dilakukan melalui rekaman kegiatan, yaitu dengan cara melihat setiap berlangsunya pengaiian Tafsir alJalalain. Rekaman kegiatan tersebut antara lain berupa foto proses pengajian, foto kitab Tafsir alJalalain para anggota pengajian dan beberapa arsip pengurus lembaga pengajian.

\section{HASIL DAN PEMBAHASAN}

\section{Festival Geridhoan dan Endhog-Endhogan}

Tradisi Geridhoan dan Endhog-Endhogan adalah serangkaian tradisi yang biasa dilakukan dalam penyambutan maulid Nabi Muhammad Shallallahu 'Alaihi Wassallam. Tradisi ini dilakukan oleh masyarakat suku Using di Kabupaten Banyuwangi. Tradisi yang unik ini jika dipasarkan dalam bentuk festival, akan menimbulkan daya tarik wisata sehingga para wisatawan akan tertarik. Hal ini sejalan dengan (Aesthetika, 2016) yang menyatakan bahwa sebuah festival akan dapat menarik minat wisatawan sehingga akan meningkatkan pendapatan daerah serta kesejahteraan masyarakat. Hal ini juga sekaligus akan meningkatkan potensi pariwisata syariah di Banyuwangi menjadi sorotan. 


\section{Dinar. Vol 6, No 2: Agustus 2019. 123-134 \\ ISSN: 2460-9889 (Cetak) \\ ISSN: 2580-3565 (Online)}

\section{a. Tradisi Geridhoan}

Geridhoan di awali dengan pemuda yang mengincar seorang gadis harus tau terlebih dahulu dimana si gadis tersebut tinggal. Kemudian, pada malam hari ketika si gadis sibuk membantu keluarganya memasak didapur, sang pemuda datang mengendap - endap untuk mengintip dan menyapa si gadis dari balik dinding dapur yang umumnya msaih terbuat dari gedheg bambu. Sambil berupaya menyapa si gadis, si pemuda juga memberi isyarat kepada si gadis tentang perasaan dan maksud kedatangannya, dengan cara memasukkan batang lidi melalui sela - sela gedheg. Dan si gadis yang sudah paham dengan isyarat tersebut kemudian meresponnya dengan cara mematahkan ujung lidi. Respons tersebut sekaligus sebagai tanda bahwa si gadis sudah mulai terbuka hatinya untuk menerima kehadiran sang pemuda. Kemudian pemuda dan gadis tersebut akan saling merayu dan ngobrol berdua, tapi tetap dibatasi oleh dinding gedheg. Dan si pemuda boleh bertamu untruk berkenalan dan menjalin hubungan lebih jauh dengan gadis tersebut dan orang tuanya. Tadisi geridhoan umumnya sampai berakhir dengan lamaran dan pernikahan.

\section{b. Tradisi Endhog Endhogan}

Endhog- endhogan adalah tradisi masyarakat Banyuwangi dalam memperingati kelahiran Nabi Muhammad SAW. Tradisi endhog - endhogan menggunakan endhog atau telur. Endhog yang digunakan dalam tradisi endhog - endhogan ditusuk dengan sebilah bambu kecil yang mirip dengan tusuk sate, namun ukurannya lebih panjang dan dihias dengan hiasan bunga dari kertas yang disebut "kembang endhog". Kumpulan dari kembang endhog di tancapkan pada batang pohon pisang yang sudah dihias yang disebut jodhang. Satu jodhang biasanya berisi kembang endhog sebanyak 33 atau 99 buah, angka yang menjadi symbol dalam islam. Kemudian kumpulan jodhang itu akan di arak atau pawai keliling kampung dengan iringan musik hadrah (rebana). Setalah itu dilaksanakn pembacaan barzanji di masjid atau mushola. Tradisi endhog endhogan di akhiri acara selamatan dengan makanan yang dihidangkan diatas ancak yang dibuat dari pelepah daun pisang. Usai acara selamatan, kembang endhog kemudian di bagi -bagikan kepada warga untuk dibawa pulang sebagai oleh - oleh.

Filosofi mengapa menggunakan telur atau endhog, karena endhog atau telur terdiri dari kuning telur, putih telur, dan cangkang, meski satu kesatuan namun memiliki makna dan filosofi yang berbeda. Kuning telur adalah embrio yang yang selanjutnya akan menghasilkan kehidupan. Iktu adalah bagian paling penting yang diibaratkan sebagai ihsan. Sedangkan putih telur yang membungkus kuning telur di ibaratkan sebagai agama islam. Sementara cangkang telur diibaratkan sebagai sebagai iman dalam kehidupan sehari hari. Jadi setelah ihsan dan islam, kemudian diperlukan iman sebagai perlindungan agar tidak sampai pudar.

Jodhang sebagai tempat menancapkan kembang endhog diibaratkan sebagai diri manusia. Jadi wujud ihsan, islam, dan iman itu harus ditancapkan pada diri manusia agar perjalanan hidupnya selalu mendapatkan rahmat dan keselamatan dunia dan akhirat. 


\section{Analisis Potensi, Peluang, dan Tantangan Festival Geridhoan dan Endhog- Endhogan}

(Rozalinda, dkk (2019) menyatakan bahwa untuk menganalisis potensi, peluang, tantangan, dan ancaman maka diperlukan matriks SWOT yang sebelumnya harus menganalisis IFAS dan EFAS. IFAS merupakan alat formula strategi yang meringkas dan mengebaluasi faktor Strenght (S) dan Weakness (W). S dan W didapatkan dari berbagai referensi terkait mengenai kekuatan dan kelemahan dari hasil wawancara ataupun referensi lainnya. EFAS merupakan faktor-faktor eksternal yang terkait dengan Opportunities (O) dan Threads (T). O dan T didapatkan dari berbagai kasus hasil wawancara maupun referensi lainnya. Setelah itu, barulah menuangkannya dalam matriks SWOT sehingga dapat dirumuskan strategi-strategi yang terdiri dari SO, WO, ST, dan WT seperti tabel di bawah ini:

\section{Tabel 1}

Strategi SO, WO, ST dan WT

\begin{tabular}{|c|c|c|}
\hline $\mathrm{NO}$ & Analisis Swot & Keterangan \\
\hline 1. & Strength (S) & Tradisi dengan nilai keislaman dan unik. \\
\hline 2. & Weakness (W) & $\begin{array}{l}\text { 1. Transportasi yang minim menuju tidak } \\
\text { dimiliki oleh daerah lain. } \\
\text { 2. Penduduk suku asing yang ramah dan } \\
\text { sering menjamu tamu yang berdatangan } \\
\text { pada saat acara dimulai. } \\
\text { 3. Fasilitas Ibadah yang memadai di tempat } \\
\text { penginapan dan di kawasan desa. } \\
\text { 4. Akses Jalan yang mudah. } \\
\text { 5. Kondisi Desa yang masih asri. } \\
\text { 6. Kesadaran masyarakat dalam menjaga } \\
\text { lingkungan }\end{array}$ \\
\hline 3. & Opportunities (O) & $\begin{array}{l}\text { 1. Menyerap tenaga kerja di daerah sekitar } \\
\text { yang dapat mengurangi pengangguran. } \\
\text { 2. Melestarikan nilai-nilai keagamaan dan } \\
\text { budaya yang di anut di masyarakat. } \\
\text { 3. Peningkatan terhadap perekonomian } \\
\text { daerah. }\end{array}$ \\
\hline 4. & Strategi SO & $\begin{array}{l}\text { 1. Melakukan inovasi baru dalam } \\
\text { mengembangkan inovasi ekonomi kreatif } \\
\text { 2. Adanya kerjasama antara paramuwisata } \\
\text { dengan pengelola daerah untuk terciptanya } \\
\text { lapangan kerja . } \\
\text { 3. Memperbaiki cirri khas daerah } \\
\text { 4. Melakukan promosi melalui media cetak }\end{array}$ \\
\hline
\end{tabular}




\begin{tabular}{|c|c|c|}
\hline & & dan media sosial \\
\hline & Startegi WO & $\begin{array}{l}\text { 1. Adanya peran dinas perhubungan dalam } \\
\text { mempermudah wisatawan menemukan } \\
\text { lokasi dengan petunjuk arah dan akses } \\
\text { transportasi } \\
\text { 2. Menyediakan pemandu wisata yang } \\
\text { mampu berbahasa asing dan pengetahuan } \\
\text { tentang adat. } \\
\text { 3. Perkembangan promosi media cetak, } \\
\text { internet, media social tradisi daerah }\end{array}$ \\
\hline 5. & Threat (T) & $\begin{array}{l}\text { 1. Muncul Wisata kuliner syariah di } \\
\text { Banyuwangi. } \\
\text { 2. Era modern yang memungkinkan } \\
\text { melunturkan budaya }\end{array}$ \\
\hline 6. & Strategi ST & $\begin{array}{l}\text { 1. Membuat konsep festival tahunan yang } \\
\text { baru dengan tidak merubah makna tradisi } \\
\text { dan adat Geridhoan dan Endhog-Endhogan. } \\
\text { 2. Melakukan sosialisasi di Pokdarwis serta } \\
\text { Karangtaruna dalam menghadapi era } \\
\text { modernisasi dengan tidak merubah } \\
\text { sedikitpun makna tradisi dan adat. }\end{array}$ \\
\hline 7. & Strategi WT & $\begin{array}{l}\text { 1. Pembangunan Infrastruktur oleh } \\
\text { pemerintah daerah dengan membantu } \\
\text { pembangunan wisata dengan tidak } \\
\text { merubah kondisi asri desa serta melakukan } \\
\text { pembinaan terhadap pemuda dalam } \\
\text { memperkokoh warisan budaya }\end{array}$ \\
\hline
\end{tabular}

Dapat disimpulkan bahwa akses jalan yang mudah menuju tempat desa, tidak sebanding dengan fasilitas transportasi dan petunjuk arah, sehingga hal ini harus dikaji serta diperbaiki lagi dengan bantuan pemerintah setempat. Dalam potensinya dengan dijadikan sebuah festival, tradisi Geridhoan dan Endhog-Endhogan di desa Macanputih, Kecamatan Kabat, Kabupaten Banyuwangi sangat berpotensi dikarenakan tradisi dengan nilai keislaman di dalamnya dan tidak ada di daerah lain dan masih dijaga turun-temurun. Selain itu pula, sifat masyarakat desa yang ramah terhadap tamu dan pendatang dapat meningkatkan ketertarikan daya tarik wisata di desa tersebut. Tentunya tradisi Geridhoan dan Endhog-Endhogan memerlukan bantuan dari pemerintah Kabupaten Banyuwangi untuk mempromosikan dalam kalender Banyuwangi Festival, sehingga selain dapat meningkatkan pendapatan daerah juga festival syariah atau konsep Halal Tourism dapat berkembang dan tentunya menjadi sorotan bagi wisatawan 


\section{Dinar. Vol 6, No 2: Agustus 2019. 123-134 \\ ISSN: 2460-9889 (Cetak) \\ ISSN: 2580-3565 (Online)}

\section{Kesimpulan}

Berdasarkan pembahasan mengenai Festival dari tradisi Geridhoan dan Endhog-Endhogan dapat disimpulkan bahwa tradisi Geridhoan dan Endhog-Endhogan sendiri adalah tradisi yang didalamnya terdapat nilai-nilai keislaman yang unik dan tidak dimiliki oleh daerah lain. Hal ini dapat meningkatkan wisatawan karena semakin unik tradisi di suatu daerah maka semakin mendorong wisatawan untuk melihat mengenai apa yang tidak ia punya. Sementara itu, Festival adalah alat sebagai pendorong untuk menambahkan wisatawan yang akan masuk dengan kerjasama dengan beberapa pihak, antara lain pengelola daerah serta pemerintah daerah setempat. Hal ini akan meningkatkan pendapatan daerah pada khususnya dan secara tidak langsung akan meningkatkan kesejahteraan masyarakat setempat karena akan banyak lapangan kerja yang terbuka.

Adapun mengenai analisis kelayakan yang dilakukan dengan menganalisis SWOT, maka dapat dismpulkan bahwa Festival Tradisi Geridhoan dan Endhog-Endhogan memiliki potensi besar dalam meningkatkan pendapatan daerah serta juga mengembangkan wisata halal di Banyuwangi. Hal ini dikarenakan tradisi ini sangat dijaga meskipun era modernisasi sudah memasuki di kawasan ini. Sifat suku osing yang terkenal ramah dan senang menjamu tamu akan juga dapat meningkatkan kepuasan wisatawan sendiri. Meskipun terdapat kelemahan dan juga ancaman luar, hal tersebut dapat dilakukan strategi yang tertera, yang antara lain butuh melibatkan pihak pemerintah demi mewujudkannya festival syariah yang optimal.

\section{DAFTAR PUSTAKA}

Aesthetika, N. M. (2016). Strategi Promosi Wisata Pulau Bawean Melalui Event Festival Molod Bawean. KANAL: Jumal Ilmu Komunikasi, 1(1), 53. https://doi.org/10.21070/kanal.v1i1.328

Alma'arif, A. (2015). Islam Nusantara: Studi Epistemologis dan Kritis. In Analisis: Jurnal Studi Keislaman.

Cheang, Vannarith. 2009. Tourismos: An International Multidisciplinary. Journal of Tourism. Vol.4, No.1 63-82

Drs. Wardiyanta, M. H. (2010). Metode Penelitian Pariwisata. 1 St.

Fallasi, A. (1997). Festival: Definition and Morphology. University of New Mexico Press, 1-10.

Hidayat Fatmah Tauvik, \& Arif, I. M. (2016). Kaedah Adat Muhakkamah dalam Pandangan Islam (Sebuah Tinjauan Sosiologi Hukum). Jumal Sosiologi USK, 9. https://doi.org/10.24815/jsu.v9i1.9262

Jaelani, A. (2017). Industri wisata halal di Indonesia: Potensi dan prospek. Mpra. https://doi.org/10.13140/RG.2.2.29350.52802

Marzuki. (2006). Tradisi Dan Budaya Masyarakat Jawa Dalam Perspektif Islam. Jurusan Ilmu Komunikasi Fakultas Ilmu Sosial Universitas Negeri Yogyakarta.

Richards, Greg. 2007. Cultural Tourism Global and Local Perspectives. NY: The Hawworth Hospitality Press 
Rozalinda, r., nurhasnah, n., \& ramadhan, s. (2019). Industri wisata halal di sumatera barat: potensi, peluang dan tantangan. Maqdis: Jurnal Kajian Ekonomi Islam. https://doi.org/10.15548/maqdis.v4i1.210

Santosa, H., \& Argubi, A. H. (2018). Potensi Pengembangan Wisata Berbasis Syariah (Halal Tourism) Di Kota Bima. Membangun Pendidikan Yang Mandiri Dan Berkualitas Pada Era Revolusi Industri 4.0 Aula. https://doi.org/10.1017/CBO9781107415324.004

Setiyawan, A. (2012). Budaya Lokal Dalam Perspektif Agama: Legitimasi Hukum Adat ('Urf) Dalam Islam. ESENSLA: Jurnal Ilmu-Ilmu Usbuluddin. https://doi.org/10.14421/esensia.v13i2.738

Wekke, I. S. (2013). Islam dan adat: tinjauan akulturasi budaya dan agama dalam masyarakat bugis. Analisis.

Widiastuti. (2013). Analisis SWOT keragaman budaya Indonesia. Jurnal Widya. Zulaekah, S., \& Kusumawati, Y. (2016). Halal dan Haram dalam Islam. Subuf. 